ERRATUM

\title{
Erratum zu: Warum herrscht Frieden in Europa?
}

\author{
John J. Mearsheimer
}

Erratum zu: Mearsheimer, J.J. (2009) Warum herrscht Frieden in Europa?

Leviathan 37(4):519-531

DOI 10.1007/s11578-009-0060-3

Dieser Beitrag wurde von Kurt Baudisch übersetzt.

(C) VS-Verlag 2010

Die Onlineversion des Originalbeitrages ist ereichbar unter doi:10.1007/s11578-009-0060-3

Prof. J. J. Mearsheimer $(\bowtie)$

Political Science Department, University of Chicago

5828 South University Ave. Chicago, IL 60637 Chicago, USA

E-Mail: j-mearsheimer@uchicago.edu 